\title{
Epidemiology of Acne Vulgaris: Prevalence, Severity and its Impact among School Teenagers in Makkah, Saudi Arabia
}

Enas H. Alfalogy ${ }^{1}$, Nahla H. Hariri ${ }^{2}$, Ibtihal T. Yamani ${ }^{3}$, Wedyan H. Al-Mosa ${ }^{3}$, Rawabi D. Majrashi ${ }^{3}$

${ }^{1}$ Family Medicine Department, Faculty of Medicine, Suez Canal University, Ismalia, Egypt.

${ }^{2}$ Community Department, College of Medicine, Umm Al-Qura University, Makkah,, Saudi Arabia.

${ }^{3}$ Medical student, College of Medicine, Umm Al-Qura University, Makkah,, Saudi Arabia.

\section{Abstract:}

Background: Acne vulgaris is one of the most prevalent chronic inflammatory dermatological problems among teenagers worldwide. It has a significant emotional and psychosocial impact on patient's quality of life. Acne vulgaris influence is found to be much higher in developing countries once compared to developed countries. Aim: to estimate the prevalence of acne vulgaris, severity, types and its influence on quality of life among Teenagers. Subjects and Methods: A cross sectional study was conducted on 196 female teenagers aged between 13-19 years who were selected randomly. They were surveyed using a self- administered questionnaire followed by a physical examination by global acne grading (GAG) system. Cardiff Acne Disability Index (CADI) was employed to evaluate effect of acne on quality of life. Results: The prevalence of acne vulgaris was (45.7\%). The majority of teenagers had acne with moderate severity (38.9\%) followed by mild acne $(30 \%)$, severe acne $(26.6 \%)$ and very severe acne $(4.5 \%)$. The mean (CADI) score was $(4 \pm 2.3)$. More than half $(56.7 \%)$ have mild disability on their quality of life, $30 \%$ have moderate disability while $13.3 \%$ have severe disability. About $40 \%$ of the teenagers reported a major concern about their skin appearance and $33.4 \%$ consider their acne a bad problem. Predictors of disability were use of cosmetic, family history, menstrual disturbance and dietary factors. Conclusions: Acne is a very common skin problem among teenagers with the majority having moderate severity with mild to moderate disability. Keywords: Acne, adolescents, disability, quality of life.

\begin{tabular}{|c|c|c|}
\hline Introduction: Acne vulgaris is one of the & Burden & (GBD).(2) \\
\hline most common chronic inflammatory & Approximately & $4 \%$ \\
\hline
\end{tabular}
dermatological diseases among adolescents. It is characterized by obstruction and/or inflammation of the pilosebaceous unit. Acne can classified as noninflammatory lesions (comedones), inflammatory lesions, or a combination of both, affecting the face frequently however, may affect the chest and the back.(1) The burden of Acne exhibits worldwide. It is considered one of the major causes of disability adjusted life years (DALYs) in the late adolescent period (15-19 year olds) in developed and developing countries according to Global dermatologists' consultations are related to Acne problems.(3) Clinically, Acne is described by a wide range of skin lesions such as comedones, papules, pustules and, may reach nodules and scarring.(4) Previous studies have reported very different prevalence rates ranging from $28.9 \%$ to $91.3 \%$ across countries.(5-7) In United States, the life time prevalence of Acne vulgaris was $80 \%$ predominantly in males.(8) Recently, most studies have demonstrated a higher prevalence rates of acne among adolescents. One study

\footnotetext{
Corresponding Author: Enas_hamdy2007@yahoo.com
} 
conducted in Lithuania among adolescents revealed that the occurrence of acne was $82.9 \%$, and was predicted by age with highest rates in the teenagers (13-19 years). ${ }^{(9)}$

Another study was conducted in Malaysia, and revealed that the prevalence of students who had facial acne was 67.5\%.(10) Similarly, The prevalence rate of Acne vulgaris among adolescents is high in Saudi Arabia $68.2 \%$ and $53.5 \%$ in Riyadh city and Northern region of Saudi Arabia consequently.(11, 12) Genetic predisposition is considered the chief primary cause of acne vulgaris. In addition, other triggering factors are documented such as androgen excess, stress, hormonal disturbances and frequent use of Cosmetic agents.(13)

Remarkably, adolescents who suffer from Acne vulgaris are susceptible to psychosocial problems such as social avoidance, depressive disorders and anxiety problems. $^{(14)}$ Overall, these studies highlighted that acne has a negative effect on adolescents' quality of life. in Makah city one study reported that $40.8 \%$ of acne patients had depression in particular female patients. ${ }^{(15)}$ Similar study was conducted in Addis Ababa, Ethiopia to estimate the prevalence and associated factors of anxiety in patients with acne which revealed that the prevalence of anxiety was $37.4 \%$ among acne patients. ${ }^{(16)}$ To our knowledge, no studies have examined the prevalence rate of acne vulgaris among adolescents in Makkah city. This study is aimed to examine the prevalence of acne vulgaris, its pattern and impact among Teenagers in Makkah city, Saudi Arabia.

Methods: A cross-sectional study was conducted among 196 teenager females who were selected using stratified random sampling technique from preparatory, secondary and high schools from $1^{\text {st }}$ November 2016 to $31^{\text {st }}$ May 2017 in Makah, Kingdom of Saudi Arabia. An informed consent was obtain from to the selected students and their parents. Students were interviewed by using a semi structured questionnaire to assess the sociodemographic

data (age, education and onset of menarche), presence of acne (onset, duration, degree, site and its pattern) and possible risk factors for acne (stress, eating habits, caffeine intake, chocolate intake, use of cosmetics, family history, menstrual irregularities and frequent face washing). Diagnosis of acne was based on physical examination findings by researchers. The examination included the face, chest and upper back regions. The acne severity was assessed using Global Acne Grading 
(GAG) System [(mild (1-18), moderate (19$30)$, severe (31-38) and very severe >39]. ${ }^{(17)}$

Students who have acne were asked to fill a self-reported Cardiff Acne Disability Index (CADI) questionnaire, Arabic version to assess the resulted disability from acne. ${ }^{(16)}$ The Cardiff Acne Disability Index is planned for use in adolescents, and even young adults with acne. CADI questionnaire includes five statements with a Likert scale, four grades (0-3). The total score ranges from 0-15. The five statements are aggressive feeling or frustration, social life disturbance, public avoidance, concern about facial appearance and an indication of how bad the acne was. The CADI score was calculated by summing the score of every statement resulting in a possible highest score of 15 and least score of 0 . CADI scores were classified as low (0-4), medium (5-9) and high (10-15). The lesser the CADI score, the minimal disability experienced by the teenager or adolescent while a greater score indicated a major disability.

Outcomes variables: Severity and disability from acne were assessed as outcome variables.

Statistical analysis: Data was investigated using IBM advanced SPSS statistical package version 23. Chi-square test was used to test the relation between categorical variables of precipitating factors. Multiple linear regression analysis was performed to conclude which of the influences were independently associated with higher CADI score in teenagers with acne vulgaris as it was normally distributed without skewness. $\mathrm{P}$ value less than 0.05 was considered significant.

Ethical considerations: Ethical approval was gained from the research and ethics committee of the faculty of Medicine at Umm Al-Qura University, Makkah, Saudi Arabia. An informed consent was obtain from to the selected students and their parents.

Results: A total of 196 teenagers were assessed aged between 13-19 years (mean \pm SD $17.2 \pm 1)$. The overall prevalence of acne was $45.7 \%$ (Figure 1). The majority of female teenagers had moderate acne in severity (38.9\%) followed by mild acne $(30 \%)$, severe acne $(26.6 \%)$ and very severe acne $(4.5 \%)$ (Figure 2). The mean of CADI score was $4 \pm 2.3$, more than half of subjects $(56.7 \%)$ have mild disability, $(30 \%)$ have moderate disability while (13.3\%) have severe disability (Figure 3). About $(40 \%)$ of the teenagers reported a major concern about their skin appearance and $(33.4 \%)$ consider their acne a bad problem (Figure 4).

The risk factors of acne vulgaris among teenagers are shown in Table 1. There was a significant relation between 
acne and family history of acne (55.6\%), menstrual disturbance (80\%), stress, $(82.2 \%)$, dietary factors $(54.4 \%)$, use of cosmetics (70\%) and frequent face washing. Table 2 presents Predictors of disability resulted from acne; they were the use of cosmetic, family history of acne, menstrual disturbance and dietary factors.

Discussion: Acne is a chronic skin disease caused by an inflammation that increases sebum production of the pilosebaceous unit. In the current study, the age group of the participants ranged from 13 to 19 years old. The prevalence of facial acne in this study was found to be $45.7 \%$ among teenaged females in Makkah, Saudi Arabia. Similar results were reported in an Australian study which found that overall prevalence of acne among male and female participants was $36.1 \%$. ${ }^{[5]}$ in addition, another study was conducted in the Northern region of Saudi Arabia, which reported the prevalence of Acne vulgaris was $53.5 \%{ }^{(12)}$. There is consistency in the rates reported in recent studies despite the variation of the assessment tools used.Different results were reported in a cross-sectional study which was conducted in Turkey and found that the prevalence of acne among high school students both male and female was $23.1 \%$ which is comparatively different and diminished. (17)] On the other hand, In
Riyadh city, the capital city, the prevalence rate of Acne vulgaris among adolescents is much higher that was $68.2 \%$ and the mean age of onset was 15.5 years ${ }^{(11)}$.

However, the low prevalence in our study may be due to the fact that our study was conducted on female participants only whereas this acne is more common in males. Furthermore the difference in prevalence rates between these studies was affected by different diagnostic criteria. In the current study, it was observed that the symptoms of acne ranging from open and closed comedones to nodules. We also used the global acne grading system for assessment acne severity. The majority of female teenagers had acne with moderate severity (38.9\%) followed by mild acne $(30 \%)$, severe acne $(26.6 \%)$ and very severe acne $(4.5 \%)$.

Comparatively, the study conducted in Muar, Malaysia showed that $87.7 \%$ of the students had mild acne, $8.4 \%$ had moderate acne, and $3.7 \%$ had severe acne. ${ }^{(10)}$ Similarly, in a study conducted among adolescents in Sao Paulo showed that majority of the participants reported to have comedones acne $(61.1 \%)$ followed by mild acne (30.6\%) and lastly moderate acne $(7.6 \%){ }^{(18)}$ The difference in distribution of severity in these studies may be due to the difference in lifestyle and risk factors of acne. 
In addition, the assessment of the effect of acne on the quality of life was done using the Cardiff Acne Disability Index. The index assessed the quality of life in teenagers suffering from acne and studied its relationship to aggressive feeling or frustration, social life disturbance, public avoidance, concern about facial appearance and an indication of how bad the acne was. The study compared these factors over the previous month. In addition, an indication was made to how bad the acne was doing presently. The mean of Cardiff Acne Disability Index was $4 \pm 2.3$ and $56.7 \%$ of subjects have mild disability, $30 \%$ have moderate disability while $13.3 \%$ have severe disability. Likewise, the study conducted in Muar, Malaysia reported (1.8\%) with score 13 in Cardiff Acne Disability Index which meant severe impairment. ${ }^{(10)}$

The current study revealed that about $40 \%$ of the teenagers reported a major concern about their skin appearance and $33.4 \%$ consider their acne a bad problem. In agreement with another study that conducted among teenaged Scottish school children as $50 \%$ of subjects had negative influence on emotions resulted from their acne. $20 \%$ of subjects had disturbances in their personal and social lives due to their acne. ${ }^{(19)}$
Furthermore, the mean of CADI score was 4.0 which is low. Overall this result indicates that the teenagers were mildly affected by acne in their lives. The high prevalence of mild acne and low prevalence of severe acne demonstrated that the impact of acne on the quality of life increased with the increase in severity of facial acne. This result is concurrent with previous studies which have shown a association between facial acne severity and the Cardiff Acne Disability Index. ${ }^{(7)}$

Conclusions: Acne vulgaris is a very common skin problem among teenagers with the majority having moderate severity.it has mild to moderate impact on the quality of life. Predictors of disability were frequent use of cosmetic, family history, menstrual disturbance and dietary factors.

Limitations of the study: Limitations of the study were that the study was conducted among females only. Short time devoted from school administrative bodies to fulfill the questionnaires and do the assessment. Refusal of some parents to examine their students.

Financial support and sponsorship: Nil. 
Conflicts of interest: The authors confirm that they have no conflicts of interest to declare.

Acknowledgements: The authors express their thanks to Abrar Ghazi Najjar, Afnan Abdullah Basallom, Asalah Fahad Alhazmi, Bashayer Abdulrahman Althaqafi, Bashair Waleed Melibari, Bushra Waleed Melibari, Bayan Muhammad Fatani, Bayan Nasser Bugis, Bayan Saud Algethami, Haneen Mohammad Banjar, Lamis Hisham Bosy, Maumounah Faisal Al-Najjar, Muruj Salah Filfilan, Rawan Osama Mirza, Raghda Talal Alsharif, Ranin Mohammed Masarit, Salwa Obed Alomeri, And Shatha Awadh Althobaiti for their help in different steps of the research such as data collection and data entry.

\section{References:}

1. Dawson AL, Dellavalle RP. Acne vulgaris. BMJ. 2013 May 8. 346:f2634.

2. Haagsma JA, Graetz N, Bolliger I, Naghavi M, Higashi H, Mullany $\mathrm{EC}$, et al. The global burden of injury: incidence, mortality, disability-adjusted life years and time trends from the Global Burden of Disease study 2013. Injury Prevention. 2016;22(1):3-1

3. Schmitt JV, Masuda PY, Miot HA. [Acne in women: clinical patterns in different age-groups]. Anais brasileiros de dermatologia. 2009;84(4):349-54.

4. Simpson NB, Cunliffe WJ. Disorders of sebaceous glands. In: Burns T, Breathnach S, Cox N, Griffiths C, editors. Rook.s Textbook of Dermatology, 7th ed., Oxford: Blackwell publishing; 2004. p. $43.1-43.75$.

5. Stathakis V, Kilkenny M, Marks R. Descriptive epidemiology of acne vulgaris in the community. The Australasian journal of dermatology. 1997;38(3):115-23.

6. Galobardes B, Davey Smith G, Jefferys M, McCarron P. Has acne increased? Prevalence of acne history among university students between 1948 and 1968. The Glasgow Alumni Cohort Study. The British journal of dermatology. 2005;152(4):824-5.

7. Goulden V, Stables GI, Cunliffe WJ. Prevalence of facial acne in adults. Journal of the American Academy of Dermatology. 1999;41(4):577-80.

8. Collier CN, Harper JC, Cafardi JA, Cantrell WC, Wang W, Foster KW, et al. The prevalence of acne in adults 20 years and older. $J$ Am 
Acad Dermatol. 2008 Jan. 58(1):56-

9.

9. Karciauskiene J, Valiukeviciene S, Gollnick H, Stang A. The prevalence and risk factors of adolescent acne among schoolchildren in Lithuania: a crosssectional study. Journal of the European Academy of Dermatology and Venereology. 2014;28(6):73340.

10. Hanisah A, Omar K, Shah SA. Prevalence of acne and its impact on the quality of life in school-aged adolescents in Malaysia. Journal of primary health care. 2009;1(1):20-5.

11. AboEl-Fetoh N, Alghamdi R, Albarqi W, Asiri S, Alruwaili N. Epidemiology Of Acne Vulgaris In Adolescent And Young Females In Riyadh City, Kingdom Of Saudi Arabia. 2016; 589-98.

12. M Abo El-Fetoh N, G Alenezi N, G Alshamari N, G Alenezi O. Epidemiology of acne vulgaris in adolescent male students in Arar, Kingdom of Saudi Arabia2016. 144$9 \mathrm{p}$.

13. Al-Huzali SA-M, K; Al-Nikhali, S \& Al-Matrafi, K. Prevalence of depression among acne patients in King Faisal Hospital and King Abulaziz Hospital in Makkah, Saudi
Arabia. International Journal of Medical Science and Public Health. 2014;3(9):1150-6.

14. Demircay Z, Seckin D, Senol A, Demir F.Patient's perspective: an important issue not to be overlooked in assessing acne severity.Eur $\mathbf{J}$ Dermatol. 2008;18:181-4.

15. Abebe $\mathrm{G}$ AG, Andargie G, Getachew M, Tesfaw G. Prevalence and Factors Associated with Anxiety among Patientswith Common Skin Disease on follow up at Alert Referral Hospital, Addis Ababa, Ethiopia. J Psychiatry. 2016;19.(367)

16. Motley RJ, Finlay AY. Practical use of a disability index in the routine management of acne. Clinical and Experimental Dermatology. $1992 ; 17(1): 1-3$

17. - Gürel MS, Yanık M, 1imßek Z, Kati M, Karaman A. Quality of life instrument for Turkish people with skin diseases. Int J Dermatol 2005; 44: 933-938.

18. Bagatin E, Timpano DL, Guadanhim LRdS, Nogueira VMA, Terzian LR, Steiner D, et al. Acne vulgaris: prevalence and clinical forms in adolescents from São Paulo, Brazil(). Anais brasileiros de dermatologia. 2014;89(3):428-35. 
19. Walker N, Lewis-Jones MS. Quality of life and acne in Scottish adolescent schoolchildren: use of the Children's Dermatology Life Quality Index (CDLQI) and the
Cardiff Acne Disability Index (CADI). Journal of the European Academy of Dermatology and Venereology : JEADV. 2006;20(1):45-50. 


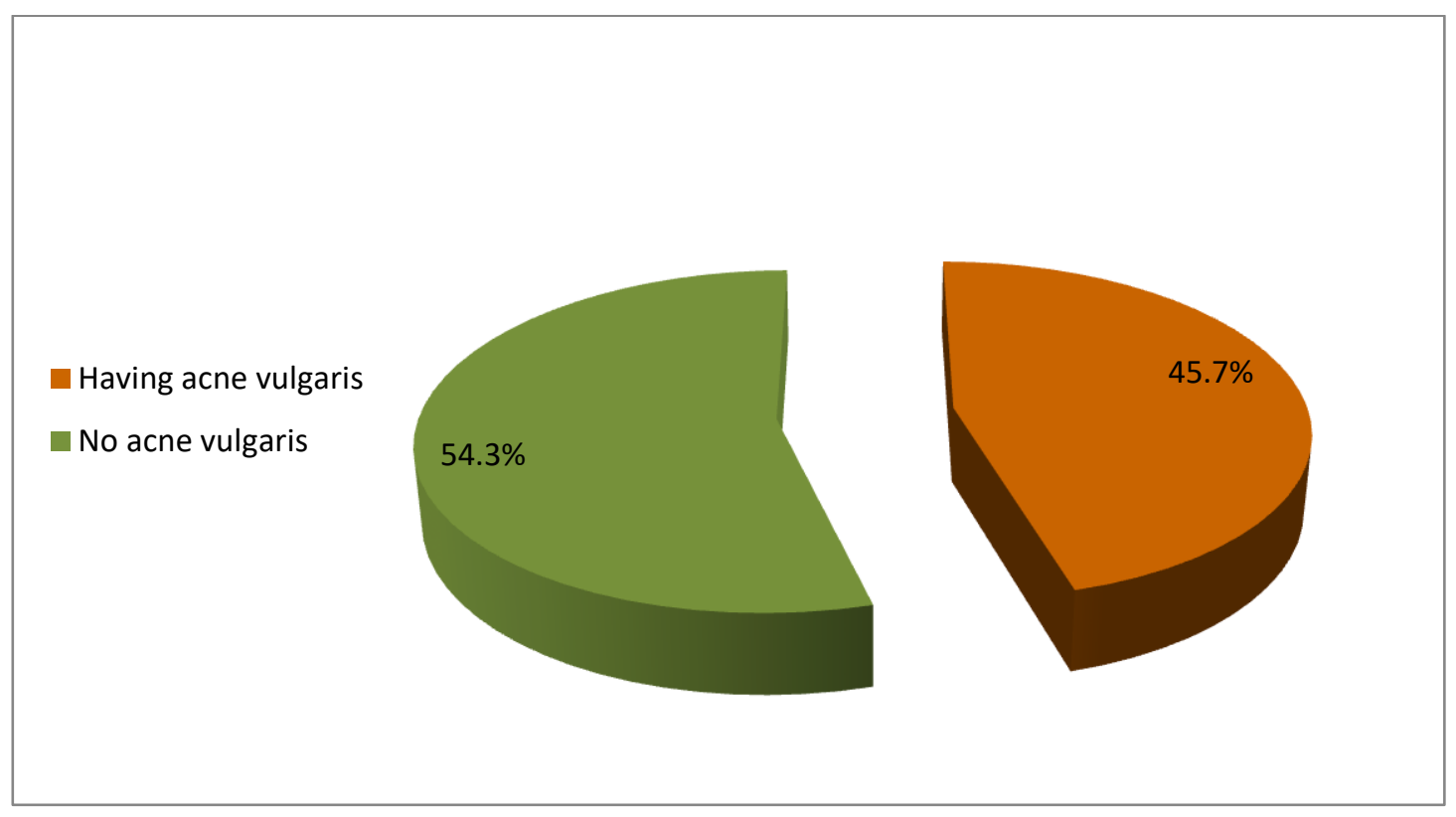

Figure (1):Prevalence of acne vulgaris among teenagers

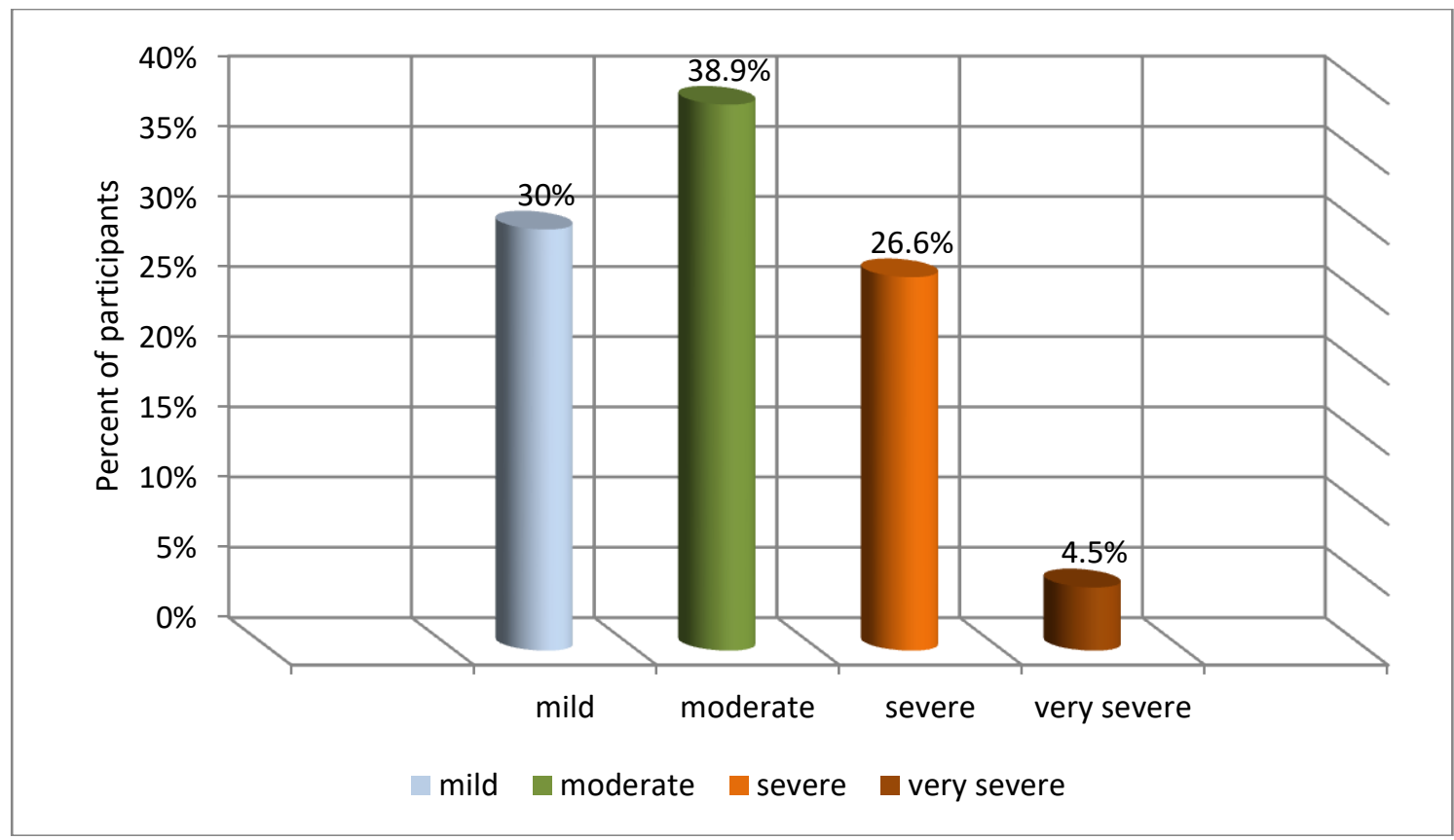

Figure (2): Severity of acne vulgaris based on GAG system. 


\section{Cardiff Acne Disability Index (CADI)}

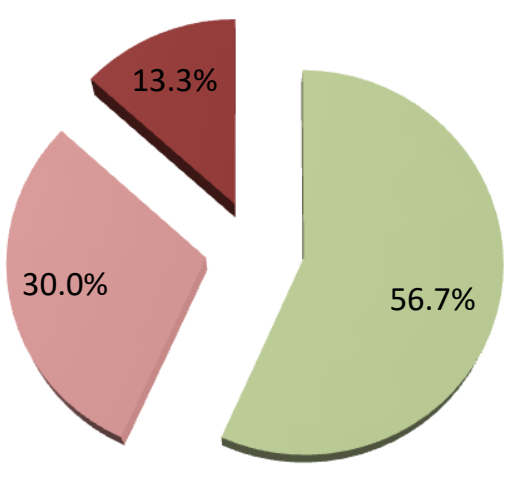

Mean $4 \pm 2.3 \quad$ Mild moderate $\square$ severe

Figure (3) : Cardiff acne disability index

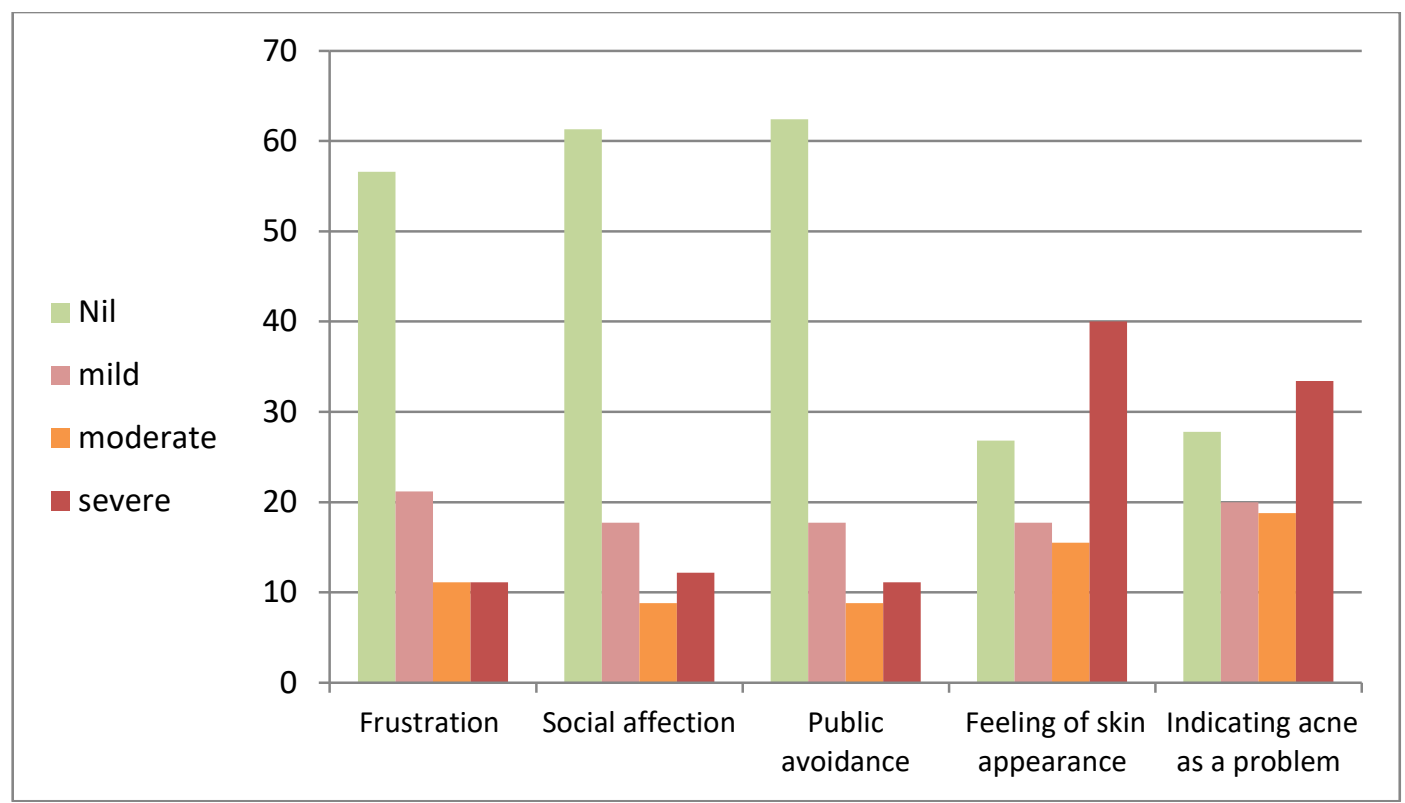

Figure (4): Domains of CADI score 


\begin{tabular}{|c|c|c|c|c|c|}
\hline \multirow[t]{2}{*}{ Risk factors } & \multicolumn{5}{|c|}{ Acne vulgaris } \\
\hline & Yes & No & Total & $\mathbf{X}^{2}$ & $\mathrm{P}$-value \\
\hline - Family history & $50(55.6 \%)$ & $9(8.4 \%)$ & $59(29.9 \%)$ & 51.787 & $<0.001$ \\
\hline $\begin{array}{ll} & \text { Menstrual } \\
\text { disturbance }\end{array}$ & $72(80 \%)$ & $13(12.1 \%)$ & $85(43.1 \%)$ & 91.741 & $<0.001$ \\
\hline - $\quad$ Stress & $74(82.2 \%)$ & $39(36.4 \%)$ & $113(57.4 \%)$ & 41.876 & $<0.001$ \\
\hline - Dietary factors & $49(54.4 \%)$ & $9(8.4 \%)$ & $58(29.4 \%)$ & 49.865 & $<0.001$ \\
\hline - Use of cosmetics & $63(70 \%)$ & $15(14 \%)$ & $78(39.6 \%)$ & 64.053 & $<0.001$ \\
\hline $\begin{array}{l}\text { Frequent face } \\
\text { washing }\end{array}$ & $28(31.1 \%)$ & $6(5.7 \%)$ & $34(17.3 \%)$ & 21.989 & $<0.001$ \\
\hline
\end{tabular}

Table (1): Risk factors of acne vulgaris among teenagers

Table (2): Multiple linear regression model for CADI for teenagers with acne vulgaris

\begin{tabular}{|c|c|c|c|c|c|c|c|}
\hline & \multicolumn{2}{|c|}{$\begin{array}{c}\text { Unstandardized } \\
\text { Coefficients }\end{array}$} & \multirow{2}{*}{$\begin{array}{c}\text { Standa } \\
\text { rdized } \\
\text { Coeffic } \\
\text { ients }\end{array}$} & \multirow[t]{2}{*}{$\mathbf{t}$} & \multirow[t]{2}{*}{ Sig. } & \multicolumn{2}{|c|}{$\begin{array}{l}\text { 95\% Confidence } \\
\text { Interval for } \mathbf{B}\end{array}$} \\
\hline & B & $\begin{array}{l}\text { Std. } \\
\text { Error }\end{array}$ & & & & Lower & Upper \\
\hline - Constant & 3.219 & 0.391 & & 8.230 & $<0.001$ & 2.448 & 3.991 \\
\hline $\begin{array}{ll}\text { - Use of } \\
\text { cosmetics }\end{array}$ & -1.606 & 0.258 & -0.347 & 6.218 & $<0.001$ & -2.115 & -1.096 \\
\hline $\begin{array}{l}\text { - Family } \\
\text { history }\end{array}$ & -1.492 & 0.260 & -0.303 & 5.743 & $<0.001$ & -2.005 & -0.980 \\
\hline $\begin{array}{ll}\text { - } & \text { Menstrual } \\
\text { disturbance }\end{array}$ & 1.423 & 0.231 & 0.311 & 6.172 & $<0.001$ & 0.968 & 1.878 \\
\hline $\begin{array}{l}\text { - } \begin{array}{l}\text { Dietary } \\
\text { factors }\end{array} \\
\end{array}$ & -0.836 & 0.277 & -0.167 & 3.014 & $<0.001$ & -1.384 & -0.289 \\
\hline
\end{tabular}

Variables excluded from model: frequent face washing and stress 


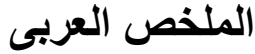 \\ وبائية حب الثباب: مدي انتشاره وشدته وتأثيره لاي المراهقين في مكة المكرمة ـ المملكة العربية السعودية}

ايناس حمدي الفالوجي- فهله الحريري- ابتهال يماني - وديان الموسا- روابي المجراشي

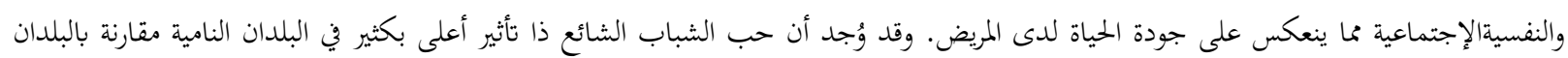

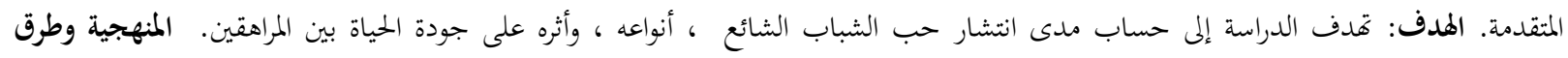

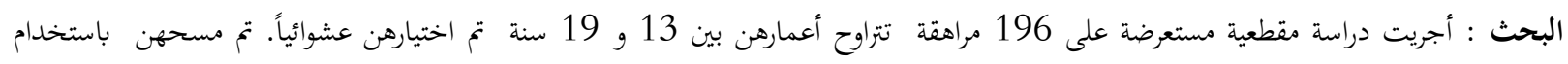

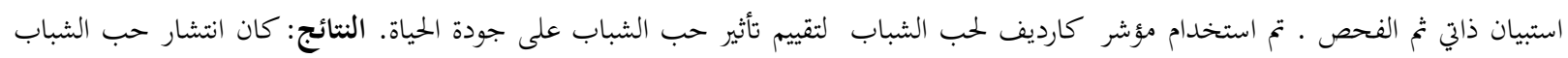

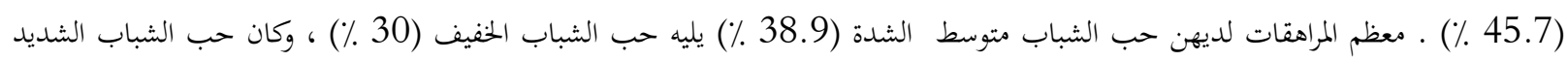

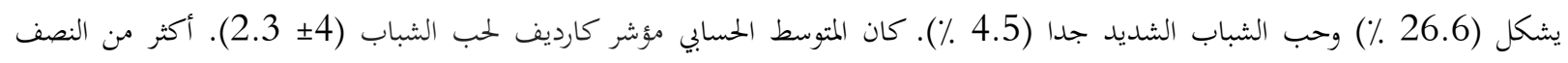

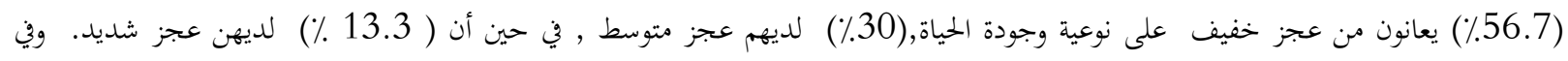

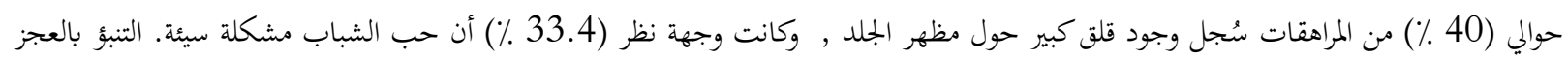

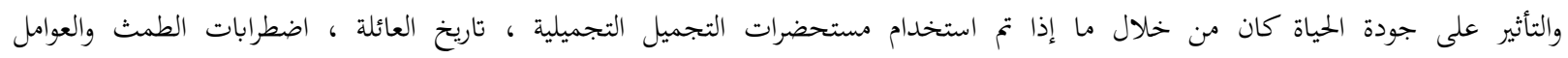

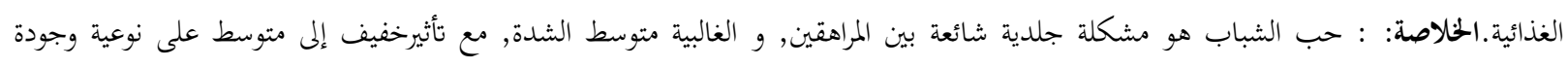

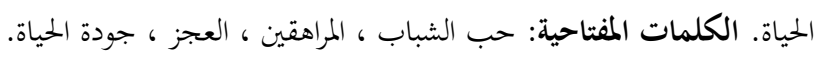

